Jurnal Kejuruteraan 30(1) 2018: 17-22

https://doi.org/10.17576/jkukm-2018-30(1)

\title{
Flow Behavior of 1.4841 Steel in Hot Compression Process
}

\author{
(Tingkahlaku Aliran Logam 1.4841 dalam Proses Mampatan Panas) \\ Javad Rajabi* \\ Department of Mechanical, Gonbad Kavoos Branch, Islamic Azad University, Gonbad Kavoos, Iran.
}

ABSTRACT

\begin{abstract}
Hot compression experiments using a dilatometer were carried out in order to study the effects of hot compression parameters on the flow behaviour of 1.4841 steel. Specifically, the effects of the strain rate and the deformation temperature within a temperature range of $950-1100{ }^{\circ} \mathrm{C}$, strain rate of 0.001-0.5 $\mathrm{s}^{-1}$ and strain value of 0.5 were studied among all the effective hot compression parameters. The results were shown in the actual strain-stress curve. Embedded in the work hardening, recrystallization and recovery theories, the hot compression mechanism was determined by focusing on the flow behaviour patterns of this steel. The sensitivity to strain rate and temperature, activation energy and the Zener - Holloman parameter were also investigated. Critical strains $(\varepsilon)$ of 0.2 and 0.35 were calculated for strain rates of 0.001 and $0.01 \mathrm{~s}^{-1}$, respectively. The findings showed that the recrystallization and flow stress fell when a deformation was imposed at a low strain rate and high temperature. A further increase in the strain rate and a decrease in the temperature resulted in a dynamic recovery mechanism as the dominant process. With an increase in the temperature, the strain rate sensitivity increased, and the rise in the strain rate resulted in a decrease in the temperature sensitivity. The temperature sensitivity $\left(\eta_{d}\right)$ for various strain rates was estimated more precisely to be within the range of 5.3 to 11.2. The $Q_{H W}$ was measured and the value was 459.186 $\mathrm{kJ} / \mathrm{mol}$.
\end{abstract}

Keywords: Dynamic recovery; Dynamic recrystallization, Temperature sensitivity parameter; Strain rate sensitivity parameter; Zener-Holloman parameter.

\section{INTRODUCTION}

Recent literatures have demonstrated that various stainless steel alloys can be used to produce casted and rolled parts. Due to its high strength, special toughness, ductility and its suitable formability in cement, oil, ceramic and furnace industries, SSA usually has been used (Nasser et al. 2001). In order to do thermomechanical process in steels, it is necessary to control parameters such as temperature, strain rate in hot deformation processes. In this process, mechanism such as WH, DRV, and DRX will be occurred simultaneously (Yang et al. 2017 \& Kim et al. 2001). When hot deformation started, dislocation density would gradually increase. Any increasing in deformation amount will lead to dislocation density increase and cross slip dislocation. As a result, Polygonization Mechanism or dynamical recovery process would happen. When the strain reaches into a critical amount, new grains will be nucleated by bulging. In this stage, DRX will be happened. Hence, the higher strain amount, the lower flow stress is reported. This condition will turn into steady state. In this stage, a kind of balance between their dislocation producing and their deletion will be created by nucleation process (Wang et al. 2005). Restoration mechanism is a function of deformation conditions i.e. temperature and strain rate in hot deformation process.

Various effects such as deformation speed and temperature have an impact on flow stress traces which can be explained by looking into dislocation mechanism as well as dynamic recrystallization in polycrystalline metals. In fact, dynamic recrystallization in phenomenon reacts to the temperature alteration and processing time. Basically, when lower strain rates are followed by higher temperatures, it leads to longer time for energy accumulation as well as causing higher mobilities at boundaries for the nucleation and dynamically recrystallized grains growth and dislocation annihilation and hence mitigate the flow stress level. In contrast to aforementioned phenomenon, higher strain rate and lower temperature increase the stress (Liu et al. 2000). On one hand, temperature can influence on atom's diffusion coeficiency, ease of movement, dislocation neutralization and sub grain boundary formation. On the other hand, it can also be effective on nucleation mechanism and dynamical recrystallization growth (Beladi et al. 2017). Furthermore, strain rate parameter is effective on how to occur restoration mechanism. In lower strain rates, when temperature is constant and there is enough time to do micro structural changes in restoration process, a decrease in flow stress will be observed. Generally, strain rate amount can influence on both dynamical recovery process resulted from dislocation movement and also recrystallization kinetic resulted from grain boundary movements (Liu et al. 2000 \& Drobnjak et al. $1997 \&$ Zhou et al. 2017). One of the most important parameters which study temperature,e effect and strain rate on flow stress is $Z$ parameter. This parameter studies the effect of strain rate directly and also temperature effects based on Arinous equation, the same as in Eq. 1: 


$$
Z=\varepsilon^{0} \exp \left(\frac{Q}{R T}\right)
$$

In this equation, $\mathrm{Z}$ is Zener-Hollomon parameter which indicates the effect of deformation condition, where $\left(\varepsilon^{0}\right)$ is strain rate, $Q$ is activation energy in hot deformation, $R$ is gas constant, $T$ is absolute temperature, where it is defined as in Eq. 2 (Kuhn and Medlin 2000):

$$
Q=\frac{R}{m} \cdot\left(\frac{\partial L n \sigma}{\partial\left(\frac{1}{T}\right)}\right) \varepsilon^{0}, \varepsilon
$$

Nowadays, the creep model is broadly applicable in constitutive equations which explain the hot deformation of metals and alloys. To correlate s (e:) in a range of temperature, the creep model introduces the Zener-Holloman parameter, the so-called temperature-compensated strain rate.

The creep model is highly precise whenever applied in explanations of the flow stress under creep deformation conditions, for instance high temperature as well as low strain rate. But, in order to predict the flow stress under non-creep deformation conditions, for instance, low temperature and high strain rate, the creep model gives rise to a relatively large error. Within creep and non-creep deformation conditions, the activation energy for deformation of non-ferrous metals, for these metals such as $\mathrm{Al}, \mathrm{Mg}$, and $\mathrm{Pb}$ is highly close to that of self-diffusion. Hence, it is recommended that the activation energy need to be adopted for self-diffusion in the constitutive equation under various deformation conditions for these metals. Furthermore, the deformation conditions have a significant impact on the activation energy for deformation for steels. In fact, the activation energy for deformation is noticeably more than that for self-diffusion. The findings of the present research investigation indicate that temperature and strain have strongly impacts on the activation energy for deformation in AISI T1 high-speed steel.

It remains to prove that Eq. 2 can elaborate both temperature and the strain rate in terms of the flow stress for any strain, and for sp and ss. For instance, McQueen et al. took up values of $0.014 \mathrm{MPa}$ for stainless steels and 0.012 MPa for HSLA steels, whereas Baragar adopted the value of 0.013 MPas for HSLA steels (McQueen et al. 1995). Karhausen and Kopp suggested that the optimum value for $\mathrm{Cr}-\mathrm{V}$ steel should be 0.007 MPa (Karhausen and Kopp 1992).

Therefore, it is recommended that the activation energy need to be adopted for self-diffusion in the constitutive equation under various deformation conditions for these metals. Furthermore, the deformation conditions have a significant impact on the activation energy for deformation for steels. Furthermore, the deformation conditions have a significant impact on the activation energy for deformation for steels (Liu et al. 2000).

In order to study strain rate effect on hot deformation process in one strain and constant temperature, parameter of strain rate sensitivity is defined. Strain rate sensitivity parameter is considered as one significant feature, so it influences on steel workability amount and it can be calculated as in Eq. 3 (Salehi et al. 2006):

$$
m=\left(\frac{\partial \operatorname{Ln} \sigma}{\partial \operatorname{Ln} \varepsilon}\right) T, \varepsilon
$$

In order to study temperature effect on hot deformation process in one strain and constant strain rate, temperature sensitivity parameter can be given as follows (Lee et al. 2006):

$$
n_{a}=\left(\frac{\partial \operatorname{Ln} \sigma}{\partial \operatorname{Ln} T}\right) \varepsilon, \varepsilon^{0}
$$

In present study, restoration process behaviors in hot steel deformation were studied to determine above equation for the considered steel.

\section{METHODOLOGY}

The steel used in this study was 1.4841 austenite stainless steel. It is produced in alloy steel complex and based on chemical analysis as shown in Table 1.

TABLE 1. Chemical compound of used steel (wt\%)

\begin{tabular}{ccccc}
\hline $\mathrm{Ni}$ & $\mathrm{Cr}$ & $\mathrm{Mn}$ & $\mathrm{Si}$ & $\mathrm{C}$ \\
\hline 20.5 & 25 & $2 \leq$ & 2 & $0.2 \leq$ \\
\hline
\end{tabular}

In present study, dilatometer techniques for evaluating thermomechanical behavior and for studying flows in high temperature have been used. Dilatometer system was that of $805 \mathrm{~A} / \mathrm{D}$ placed in research center and steel engineering alloy steel Esfahan complex. After a practical and comprehensive study, steel specimens with precise dimension and suitable geometry and advised surface conditions were prepared in a suitable direction and specific areas in ingots. Firstly, discs with $1 \mathrm{~cm}$ in thickness from forged barreled ingot were identified. They were cut without any fault in macroscopically studies and in radius direction with values in the range of $1 / 3 \sim 2 / 3(\mathrm{~cm})$ radius, dilatometer specimens with $5 \mathrm{~mm}$ in diameter and $7.5 \mathrm{~mm}$ in height were prepared. Reactions of lubricant moving out friction and correction of sample flow pattern were identified referring previous experimental studies (Zhou et al. 2017). In this regard, in two up and down surfaces, useless cone samples including $136^{\circ}$ pinnacle angle were evacuated by mechanizing method. In addition, a glass past dough for fully omitting the efficiency effect was used. Here, barreling effects were not generally been observed after hot deformation operation: (1) Imposed thermomechanical cycles to samples consisted of austenite treatment for $7.5 \mathrm{~min}$ in temperature of $1150^{\circ} \mathrm{C}$ and (2) cooling up to deformation temperature in $1100,1000,950^{\circ} \mathrm{C}$ 
by imposing strain value $(=0.5)$ which their strain rates was respectively $=0.001,0.01,0.1,0.5 \mathrm{~s}^{-1}$. Finally, all specimens were cooled from deformation temperature at constant and fast period (20 s) to environment temperature. Optimum results of thermomechanical test consist of stress - strain curves. Stress - strain curves indicated flow behaviors of material in various temperatures and strain rate. The effects of strain rate and temperature in Zener-Hollomon parameter in all thermomechanical cycles were evaluated.

\section{RESULTS AND DISCUSSION}

This section provides results for each experimental works of hot compression. Figure 1(a) to Figure 1(d) show experimental results of hot compression of 1.4841 austenitic stainless steel in various of strain rate and temperature (true stress- strain curve). Table 2 provides explanation on this determined curve using the mechanism in different conditions.
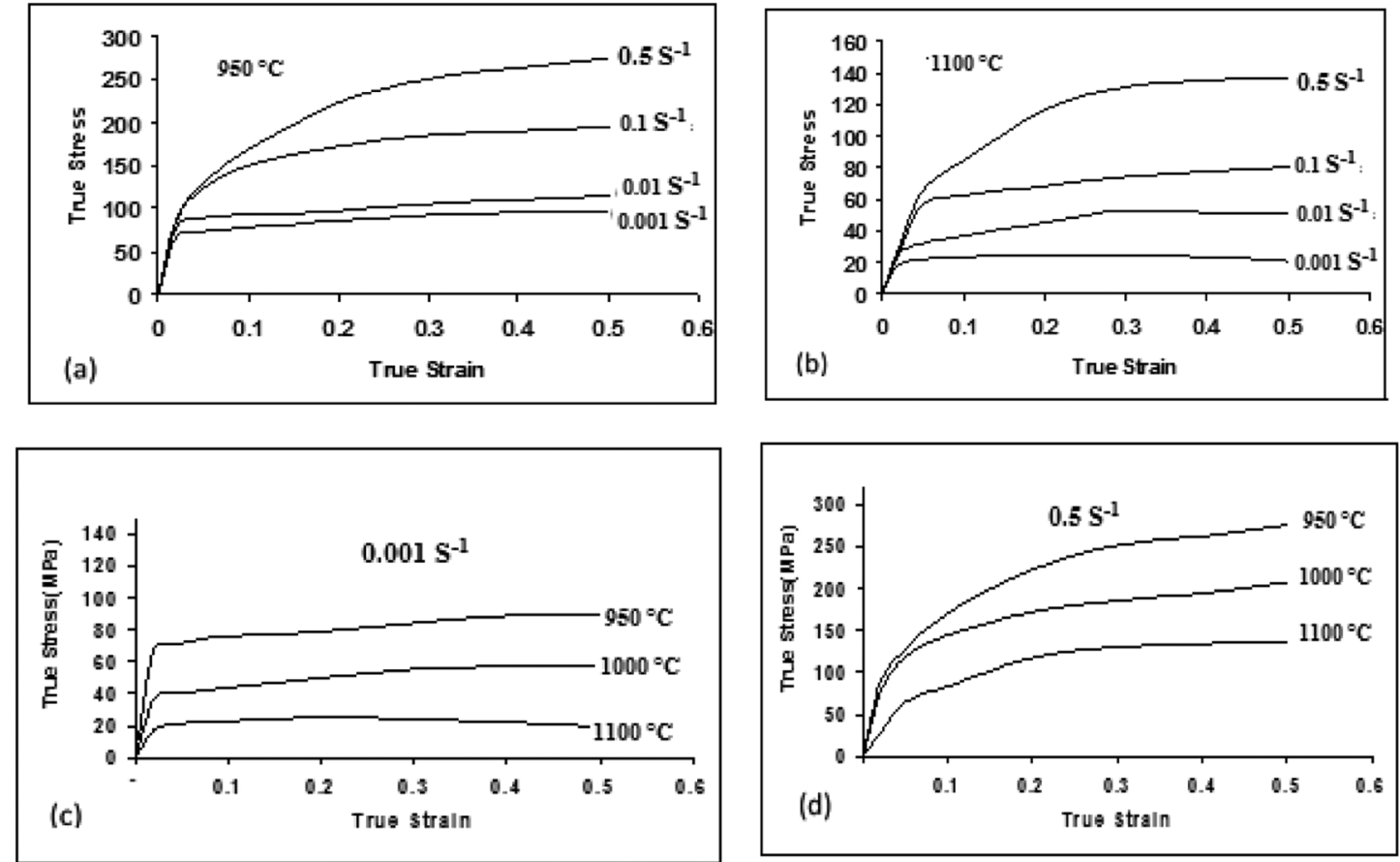

FIGURE 1. 1.4841 Austenitic stainless steel flow curves under: a) different strain rates in $950^{\circ} \mathrm{C}, \mathrm{b}$ ) different strain rates in $1100^{\circ} \mathrm{C}, \mathrm{c}$ ) different temperatures in $0.001 \mathrm{~s}^{-1}$-strain rate and d) different temperatures in $0.5 \mathrm{~s}^{-1}$-strain rate

TABLE 2. Effect of strain rate and deformation temperature on the flow curve of 1.4841 austenitic stainless steel

\begin{tabular}{|c|c|c|c|}
\hline$\varepsilon^{0} \mathrm{~T}$ & 950 & 1000 & 1100 \\
\hline $0.001 \mathrm{~s}^{-1}$ & $\sigma_{\max }=96.8 \mathrm{MPa}($ Dynamic recovery) & $\sigma_{\max }=58.7 \mathrm{MPa}$ (Dynamic recovery) & $\begin{array}{l}\sigma_{\max }=25.1 \mathrm{MPa} \text { (Dynamic) } \\
\varepsilon_{\text {rec }}=0.2 \text { (Recrystallization) }\end{array}$ \\
\hline $0.01 \mathrm{~s}^{-1}$ & $\sigma_{\max }=100.8 \mathrm{MPa}$ (Dynamic recovery) & $\begin{array}{l}\sigma_{\max }=103 \mathrm{MPa} \text { (Dynamic recovery } \\
\text { after work hardening) }\end{array}$ & $\begin{array}{l}\sigma_{\max }^{\mathrm{rec}}=52.5 \mathrm{MPa} \text { (Dynamic) } \\
\varepsilon_{\mathrm{rec}}=0.35 \text { (Recrystallization) }\end{array}$ \\
\hline $0.1 \mathrm{~s}^{-1}$ & $\begin{array}{l}\sigma_{\max }=201.9 \mathrm{MPa} \text { (Dynamic recovery } \\
\text { after work hardening) }\end{array}$ & $\begin{array}{l}\sigma_{\max }=135.5 \mathrm{MPa} \text { (Dynamic recovery } \\
\text { after work hardening) }\end{array}$ & $\sigma_{\max }=80.3 \mathrm{MPa}$ (Dynamic recovery) \\
\hline $0.5 \mathrm{~s}^{-1}$ & $\sigma_{\max }=262 \mathrm{MPa}$ (Dynamic recovery) & $\sigma_{\max }=210 \mathrm{MPa}$ (Dynamic recovery) & $\sigma_{\max }=137.1 \mathrm{MPa}$ (Dynamic recovery) \\
\hline
\end{tabular}

\section{EFFECT OF STRAIN RATE}

Referring to Figure 2, any increase in strain rate would result in the increase in stress. More precisely, it will increase austenite phase strength. In one specific strain, when sample strain rate increases, the sample will reach into a higher level of energy. It can be seen that the strain corresponding to the peak flow stress increases with the decrease in temperature and with the increment of strain rate. The peak flow stress decreases slowly after the strain reached its peak value consequently, dynamic recrystallization (DRX) acts as the main softening mechanism during deformation. However, decreasing temperature and increasing strain rate will delay the onset of DRX. Figure 1 shows the dependence of peak flow stress on temperature. The sudden change in the slope of the lines in Figure 1 may be related to the dynamic precipitation process, which retards the onset of DRX. This phenomenon has been reported in previous investigations. 


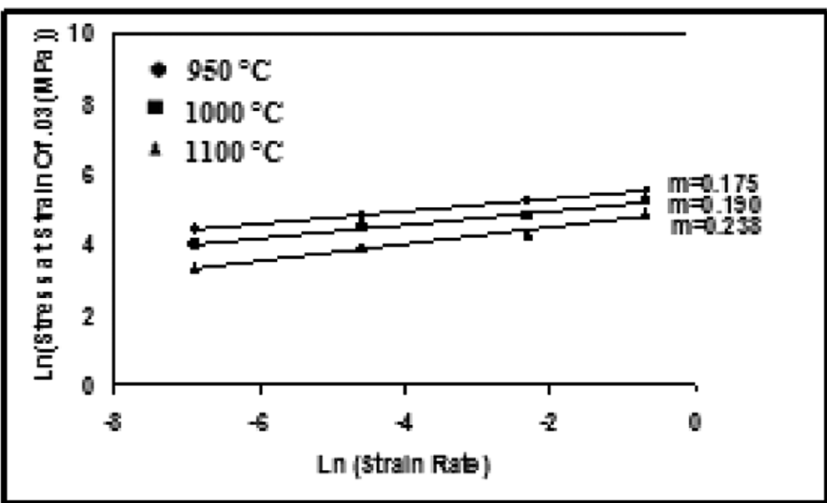

FIGURE 2. Effect of strain rate on peak stress in different temperatures

As a result, dislocation speed will increase and thereafter, dislocations will hit to the blockages much sooner and finally this process will stop. Dislocation density will increase more because of this stoppage. Its direct influence is to increase flow stress (Beladi et al. 2017). Any increase in strain rate in constant temperature would result in recrystallization in more strains at times shorter. In other words, a delay is observed. As shown in Table 2, in $1100{ }^{\circ} \mathrm{C}$, critical strain $\left(\varepsilon_{c}\right)$ was calculated on strain rates $0.001,0.01 \mathrm{~s}^{-1}$ respectively $0.2,0.35$. Dynamic recrystallization process will change into dynamic recovery when strain rate rises at this temperature. The most general equation to show the effect of strain rate on flow stress is the same as follows:

$$
\sigma=c \varepsilon^{0^{m}}
$$

where $\mathrm{m}$ is called strain rate sensitivity parameter. It should be noted that this parameter can be calculated by line slope $\left(\operatorname{Ln} \sigma-\operatorname{Ln} \varepsilon^{0}\right)$.

Considering calculated sensitivity parameters $(\mathrm{m})$ from line slope of Figure 3, it can be observed that this parameter is variable and when temperature increases, it will raise.

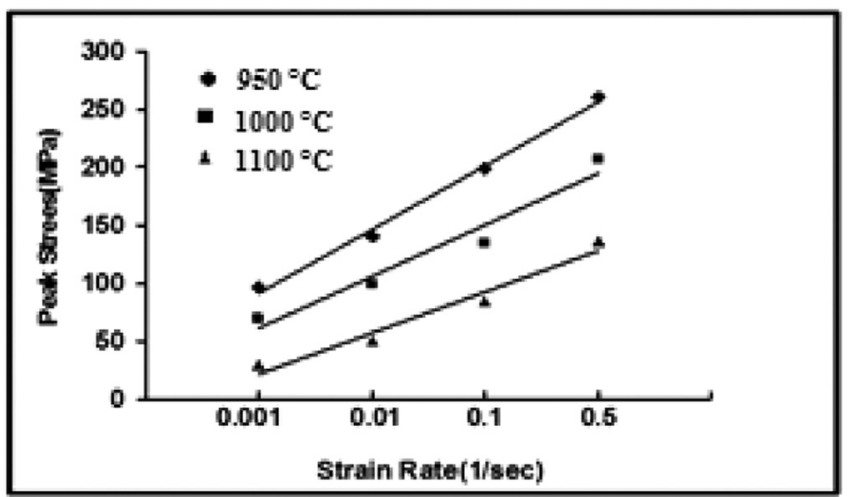

FIGURE 3. Slope of stress changes in terms of strain rate in order to determine parameter $(\mathrm{m})$
Any increase strain rate sensitivity in high temperature is related to the increase in process rates activated by heat. Processes such as dislocation climb and grain slip are the best ones to mention. Figure 4 also shows the relationship between strain rate sensitivity and temperature. Any increase in strain rate sensitivity value can be due to DRX in high temperature where they have high strain rate sensitivity value compared to low temperature (Salehi et al. 2006; Lorenz et al. 2003).

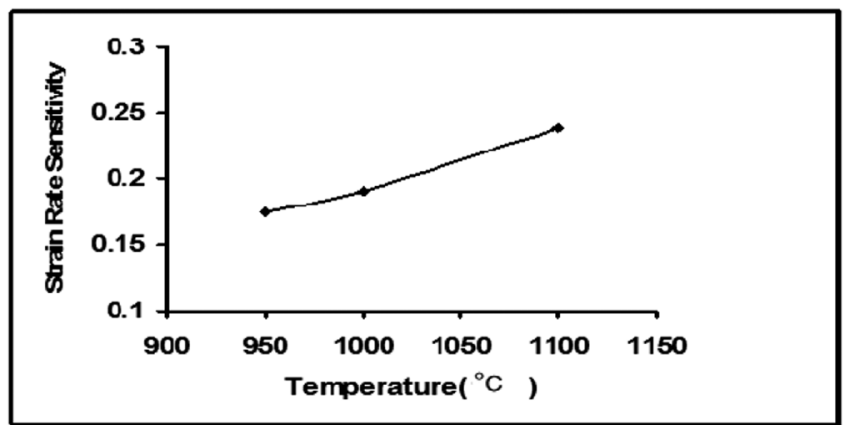

FIGURE 4. The effect of temperature on sensitivity to strain rate parameter $(\mathrm{m})$

TEMPERATURE EFFECT

As shown in Figure 1, temperature can provides the impacts clearly on the flow stress. When temperature increases, dislocation movement can easily happen. This results in a decrease in dislocation density. Therefore, flow stress for every strain value at high temperatures is less than low temperatures and material resistance against deformation will also decrease (Lee et al. 2006). As shown in Figure 1(c) when in constant strain value and any increase in temperature, recovery process will change into dynamic recrystallization. That is because, any increase in temperature rises can result in an increase in nucleation and growth speed. In fact, if the temperature increases, activation of atoms will grow. So, subgrain boundary and anile twins can act as main centers of recrystallization nucleation formation and can quickly be formed to accelerate dynamic recrystallization (Mohammed et al. 2014). Temperature sensitivity parameter $\left(\eta_{2}\right)$ expresses temperature effect on steels when strain and strain rate is constant. This parameter can be calculated by slope line (Lnstress - LnT) as shown in Figure 3 and 5 respectively. Figure 5 shows a more precise analysis on the obtained temperature at which the values for various strain rates were estimated more precisely in the range from 5.3 to 11.2. Hence, it can be found that an increase in strain value will result in temperature value. 


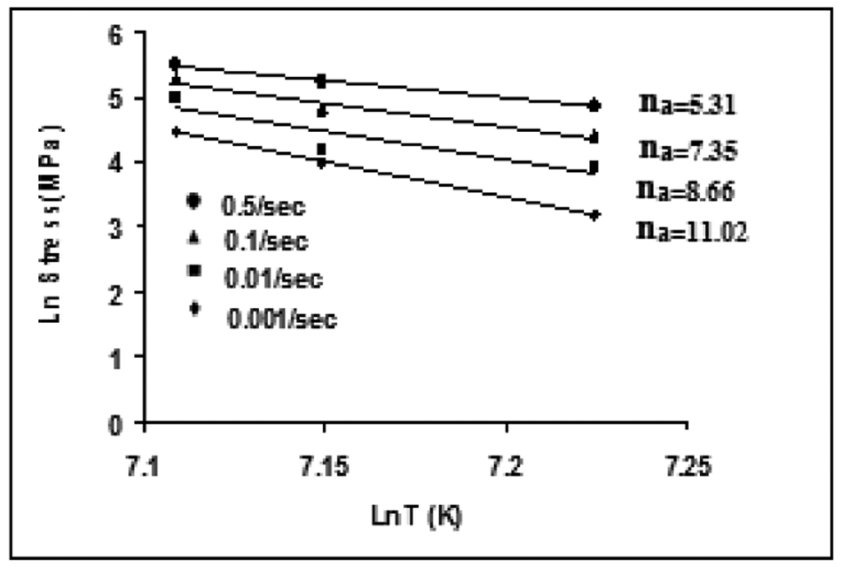

FIGURE 5. The slope of temperature changes in terms of stress in order to determine $\mathrm{n}_{\mathrm{a}}$

THE EFFECT OF TEMPERATURE AND STRAIN RATE COMBINATION

Both parameters such as temperature and strain rate will be collected in a parameter called Zener - Hollomon. Its advantage is to measure changes of both parameters more easily. These parameter changes can change DRX behavior in to DRV one. With regard to Table 2, austenite stainless steel with more alloys element in a delay phenomenon or recrystallization non observance can be seen. In addition, low strain rate and high-temperature ( $\mathrm{Z}$ falling) recrystallization is more likely to happen since there is enough time for the new phase nucleation. So when strain value increases and temperature decreases ( $\mathrm{Z}$ increasing), dynamic recovery is the most observed event. To determine (Z), according to Eq. 1, $Q_{H W}$ amount should be measured. In this study, $Q_{H W}$ is measured about $459.186 \mathrm{~kJ} / \mathrm{mol}$ using Eq. 2, Figure 6 and Figure 7. From thermomechanical perspectives, the $Q_{H W}$ enables dislocations to overcome short-range barriers.

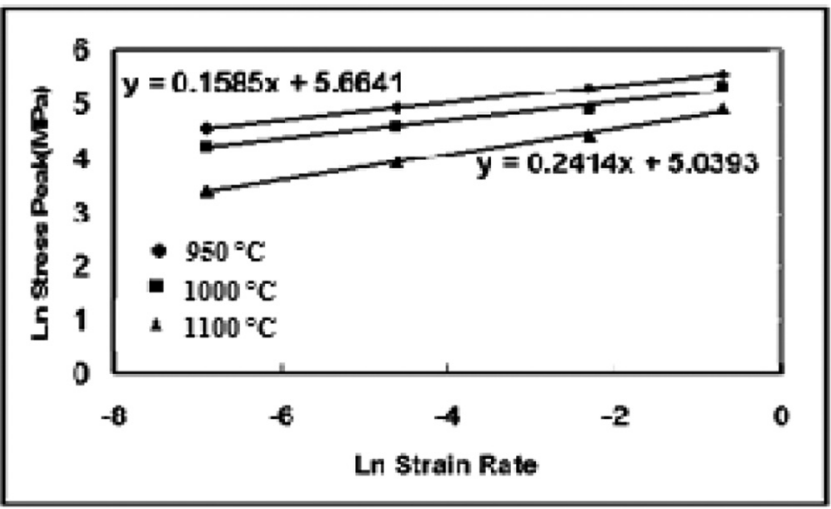

FIGURE 6. The slope of Peak stress changes according to strain rate in order to determine parameter $(\mathrm{m})$

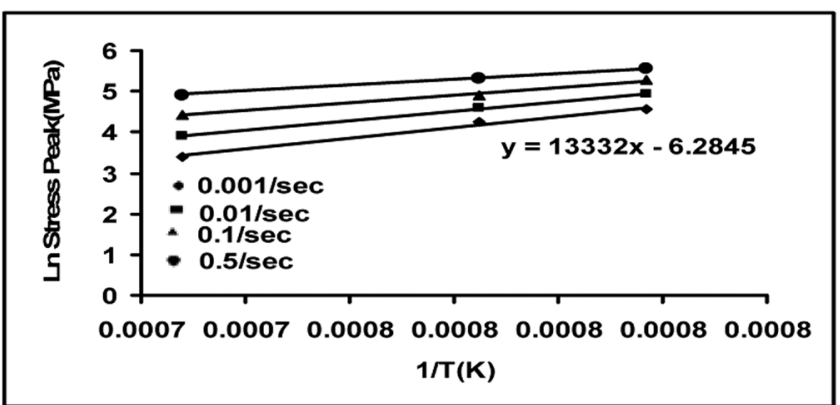

FIGURE 7. The slope of $\mathrm{p}$ eak stress changes according to absoulate temperature in order to determine $\mathrm{Q}_{\mathrm{HW}}$

Thermodynamically, $Q$ makes dislocation dominant on short - range barriers. Hence, an increase in the $Q$ causes a material resistance reduction against deformation. Consequently, $Z$ parameter can be shown in this experimented temperature range as follows:

$$
\mathrm{Z}=\varepsilon^{0} \exp (459.186 / \mathrm{RT})
$$

In plastic deformation of at low strain rates and at ambient temperature or above (i.e. with a low Z), refinement of coarse grains is dominated by dislocation activities by forming various dislocation configurations, including dislocation cells, walls, geometry necessary boundaries and incidental dislocation boundaries. These dislocation cells gradually transform into sub grains separated by boundaries of small miss orientations (from dislocation cell walls). With increasing strain, miss orientations of the sub grain boundaries increase, forming high-angle GBs so that refined grains are randomly oriented. With this mechanism, the eventual grain size is determined by the dislocation cell size.

\section{CONCLUSION}

Increasing strain rate while the temperature is kept constant would result in recrystallization in more strains at times shorter. Any increase in strain rate sensitivity at high temperatures is pertinent to the increase in process rates activated by heat such as dislocation climb and grain boundary slip. On the other hand, any increase in strain rate sensitivity value can be due to DRX at high temperatures, where they have high strain rate sensitivity value as of at low temperatures. Flow stress for every strain value at high temperatures is less than low temperatures and material resistance against deformation will also decrease. Any increase temperature in constant strain value cause to recovery process will change into dynamic recrystallization. Parameter zener-Holloman has been fallen in high strain rate and temperature and also recrystallization is more likely to happen since there is enough time for the new phase nucleation. Dynamic crystallization happens in lower critical strain due to alloy elements of 1.4841 Alloy Stainless Steel when temperature is high and strain rate is low. 
REFERENCES

Beladi, H., Cizek, P., Taylor, A.S., Rohrer, G.S. \& Hodgson, P.D. 2017. Static softening in a Ni-30Fe austenitic model alloy after hot deformation: microstructure and texture evolution. Metallurgical and Materials Transactions A 48(2): 855-867.

Drobnjak, D., Radovi, N., Andjeli, M. \& Koprivica, A. 1997. Effect of test variables on apparent activation energy for hot working and critical recrystallization temperatures of V-microalloyed steel. Steel Research International 68(7): 306-312.

Karhausen, K. \& Kopp, R. 1992. Model for ntegrated process and microstructure simulation in hot forming. Steel Research International 63(6): 247-256.

Kim, S.I. \& Yoo, Y.C. 2001. Dynamic recrystallization behavior of AISI 304 stainless steel. Materials Science and Engineering: A 311(1): 108-113.

Kuhn, H. \& Medlin, D., 2000. ASM Handbook. Volume 8: Mechanical Testing and Evaluation. ASM International, Member/Customer Service Center, Materials Park, OH 44073-0002, USA, 2000. 998.

Lee, W.S. \& Liu, C.Y. 2006. The effects of temperature and strain rate on the dynamic flow behaviour of different steels. Materials Science and Engineering: A 426(1): 101-113.

Liu, J., Chang, H., Wu, R., Hsu, T. \& Ruan, X. 2000. Investigation on hot deformation behavior of AISI T1 high-speed steel. Materials Characterization 45(3): 175-186.

Lorenz, U. \& Esser, J.J. 2003. Homogeneity of deformation. Materialprufung 38(10): 449-454.

Mcqueen, H., Yue, S., Ryan, N. \& Fry, E. 1995. Hot working characteristics of steels in austenitic state. Journal of Materials Processing Technology 53(1-2): 293-310.

Mohammed, M.N., Omar, M.Z., Syarif, J., Sajuri, Z., Salleh, M.S. \& Alhawari, K.S., 2014. Microstructural properties of semisolid welded joints for AISI D2 tool steel. Jurnal Kejuruteraan 26: 31-34.
Nemat-Nasser, S., Guo, W.G. \& Kihl, D.P. 2001. Thermomechanical response of AL-6XN stainless steel over a wide range of strain rates and temperatures. Journal of the Mechanics and Physics of Solids 49(8): 1823-1846.

Salehi, A.R., Serajzadeh, S. \& Yazdipour, N. 2007. A study on flow behavior of A-286 super alloy during hot deformation. Materials Chemistry and Physics 101(1): 153-157.

Wang, B.X., Liu, X.H. \& Wang, G.D. 2005. Dynamic recrystallization behavior and microstructural evolution in a Mn-Cr gear steel. Materials Science and Engineering: A 393(1): 102-108.

Yang, J., Wang, G., Jiao, X., Li, X. \& Yang, C. 2017. Hot deformation behavior and microstructural evolution of $\mathrm{Ti} 22 \mathrm{Al} 25 \mathrm{Nb} 1.0 \mathrm{~B}$ alloy prepared by elemental powder metallurgy. Journal of Alloys and Compounds 695: 1038-1044.

Zhou, P., Ma, Q. \& Luo, J. 2017. Hot deformation behavior of as-cast $30 \mathrm{Cr} 2 \mathrm{Ni} 4 \mathrm{MoV}$ steel using processing maps. Metals 7(2): 50-57.

*Javad Rajabi

Department of Mechanical,

Gonbad Kavoos Branch,

Islamic Azad University,

Gonbad Kavoos, Iran.

"Corresponding author; email: rajabi.javad@gmail.com

Received date : $29^{\text {th }}$ July 2017

Accepted date $: 29^{\text {th }}$ January 2018

In Press date : $1^{\text {st }}$ April 2018

Published date : $30^{\text {th }}$ April 2018 